\title{
Importance of Tooth Brushing in Pediatrics-A Short Review
}

\author{
Stuti Mohan* \\ Department of Orthodontics \& Dentofacial Orthopedics, DJ College Of Dental Sciences \& Research, India

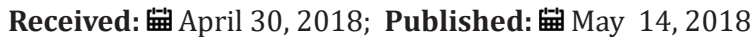 \\ *Corresponding author: Stuti Mohan, Deptartment of Orthodontics \& Dentofacial Orthopedics, Uttar Pradesh, Modinagar, India
}

\begin{abstract}
A poor oral hygiene or any oral disease affects the oral health and then ultimately the general health of a person which in return influences the overall appearance of a person. Thus it is very important to take a good care of oral health. Oral hygiene is the practice of keeping the mouth clean and healthy by brushing and flossing to prevent gum diseases and tooth decay. It is done in order to prevent the plaque and food deposit on tooth thus to prevent caries and cavities.
\end{abstract}

Abbreviations: AAPD: American Academy of Pediatric Dentistry; ADA: American Dental Association

\section{Introduction}

Good oral hygiene should start at an earlier age than what is generally believed. And more important is to start taking take good care of oral care from childhood, along with acquiring habits for its maintenance, it is something that allow adults to keep their teeth healthy throughout their lifetime [1].Teaching the child a proper oral care at a young age is an investment in his or her health that will pay lifelong dividends. By taking a good care of their own teeth, one can send a message that maintaining good oral health is actually is of great value [2]. The American Academy of Pediatric Dentistry (AAPD) recommends that infants should consult the dentist within 6 months of getting their first tooth or by their first birthday [3]. The American Dental Association (ADA), also recommends to bring baby to the dentist as soon as the first tooth appears in oral cavity and no later than the child's first birthday. This visit gives dentist a chance for a closer look and to check for tooth decay and discuss other conditions or habits, such as thumb sucking that may affect the teeth in later stages. The dentist also can show how to clean baby's teeth properly [4]. After every feeding, a clean, warm wash cloth should be used to gently cleanse the inside of the mouth [5]. 2 Oral tissues should be regularly checked by the parents for any breach or trauma.

It is recommended to visit dentist regularly, based on the child's oral health [3]. By taking proper measure one can maintain good oral hygiene

\section{First step in maintenance of oral hygiene is the selection of a good tooth brush}

There are several factors that one should consider when choosing a toothbrush but the main ones are [2]:

a) A soft bristled toothbrush should be chosen as they are flexible which can easily

b) Reaches to all areas of the teeth even the hard to reach areas.

c) Soft bristles tooth brushes, doesn't cause bruising of gums and wear and tear of teeth.

d) The head of the brush should be small so that it can effectively clean all the areas of the teeth.

e) The handle of the tooth brush should be of comfortable gripping by the user.

f) Toothbrushes should be replaced in the following circumstances [6].

g) After every 3 months of use, toothbrush should be replaced by a new one.

h) After a cold or illness, tooth brush should be changed immediately. 
i) When the bristles lose their shape, change the tooth brush.

\section{Secondly, selecting the good toothpaste}

a) Toothpaste is a valuable adjunct to a toothbrush in oral hygiene, but it is the correct brushing action that removes the plaque from your teeth [7].

b) Most toothpaste contains fluoride, which helps to prevent and control cavities. A tube of fluoride toothpaste contains fluoride (1,000 to $1,500 \mathrm{ppm})$. It's important to use one with the right concentration of fluoride for your child $[8,9]$.

\section{Flossing 2}

a) It should be started once any two of child's teeth comes in contact with each other. Due to tight contacts, sometimes food get caught between the teeth, thus flossing helps in removal of lodged food particles hence preventing cavities by removing plaque.

b) Children should be able to floss their own teeth by the time they are 9 years old.

c) Other important measure to prevent tooth decay:

d) To rinse well with plain water after every meal specially after sweets.

e) To brush atleast twice a day.

f) As soon as first sign of caries is noticed, should see family dentist immediately.

g) Do visit a dentist in every 6 months.

\section{Conclusion}

Dentists plays an important role in the primary prevention of dental problems in young children through preventive treatments, risk assessment, and anticipatory guidance for parents regarding oral development, caries prevention, and overall oral health [9]. Recommendations for at-home preventive measures, including brushing of infants' and young children's teeth and using fluoride toothpaste, are key elements of anticipatory guidance to be provided to parents by the child's dental home [10]

\section{References}

1. http://www.dentaid.com/en/childrens-oral-hygiene.

2. Sanjeev Julka, Neha Pandey (2014) Essentials of Oral Hygiene Measures For Children And Anticipatory Guidance For The Care Providers. Annals of Dental Specialty 2(3): 97-99.

3. Abdulrahman Alshehri, VS Nasim (2015) Infant Oral Health Care Knowledge And Awareness Among Parents In Abha City Of Aseer Region, Saudi Arabia. The Saudi Journal for Dental Research 6(3): 98-101.

4. JADA 145(5) http://jada.ada.org May 2014- For the patient: Taking care of your child's smile.

5. Kowash MB, Pinfield A, Smith J, Curzon ME (2000) Effectiveness on oral health of a long term health education for mothers with young children. Br Dent J 188(4): 201-205.

6. Bastiaan RJ (1986) The cleaning efficiency of different toothbrushes in children. J Clin Periodontol 13(9): 837-840

7. American Academy of Pediatric Dentistry (2009) Policy on early childhood caries (ECC): Classifications, consequences and preventive strategies. Pediatr Dent 30(7): 40-43.

8. American Academy of Pediatric Dentistry (2009) Guideline on fluoride therapy. Pediatr Dent 30(7): 121-124.

9. AAPD, Council on Clinical Affairs (2008) Guideline on infant oral health care.

10. AAPD, Council on Clinical Affairs (2008) Policy on early childhood caries: Classifications, consequences, and preventive strategies.

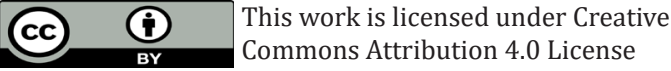

To Submit Your Article Click Here:

Submit Article

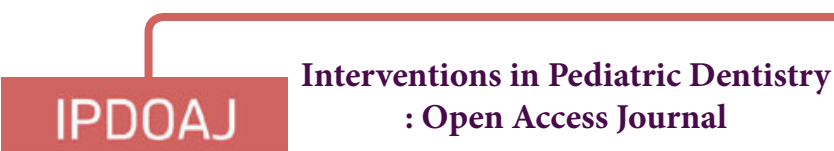

Assets of Publishing with us

- Global archiving of articles

- Immediate, unrestricted online access

- Rigorous Peer Review Process

- Authors Retain Copyrights

- Unique DOI for all articles 